\title{
The chicken or the egg? Investigating the transformational impact of learning technology
}

Janet F. Buchan*

Division of Learning and Teaching Services, Charles Sturt University, Australia

(Received 30 January 2010; final version received 29 April 2011)

This study aimed to investigate the transformational impact of introducing significant new learning technology in an Australian university over the time period 2007-2009. The exploration of this transformation is grounded in a social-ecological systems approach to the management of technology enhanced learning environments in the face of constant change. The transformational impact is described using the Adaptive Cycle Framework. The single case study had a whole-of-institution systems focus. Data collection targeted a variety of stakeholders involved in the use of, support for users of, implementation and maintenance of learning technology. A variety of data collection methods were used including interviews, document collection and a reflective journal. The research shows that learning technology has significant transformational potential at both individual and at institutional levels. However, this study has unearthed a 'chicken or the egg' conundrum. Although learning technology is an important part of the future of educational institutions, the adaptability of the organisation and capacity to predict, plan for and support ongoing changes in learning technology is an important part of realising the transformational potential and effectiveness of learning technology.

Keywords: transformation; learning technology; online learning environment; adaptive cycle framework; learning management system; para-analysis

\section{Introduction}

This study aimed to investigate the transformational impact of introducing of a new online learning environment (OLE) in a regional Australian university over the time period 2007-2009. The exploration of this transformation is grounded in the Adaptive Cycle Framework (Buchan 2008a, 2008b) and this study aims to develop this framework further. The Adaptive Cycle Framework forms part of a social-ecological systems approach to the management of the learning environment (Cumming et al. 2006; Walker et al. 2006; Buchan 2008b). The social-ecological systems approach has both a temporal and physical basis and requires that one takes a holistic view of the learning environment. This approach informs the basic premise in this research; that is, one must focus at two levels, individual and institutional, when investigating aspects of learning technology such as its transformational potential.

*Email: jbuchan@csu.edu.au 


\section{Background}

The simplest definition of transform is 'to change' (Collins Concise Dictionary), and at an institutional level, transformation has been noted as one kind of change (Kezar 2003). It is appropriate that in defining transformation in higher education we place value on the learning that takes place during a transformation. Transformational learning (a term used interchangeably with transformative learning) is a topical area of research (McKewen 2009). Transformational learning has been described as "the expansion of consciousness through the transformation of basic world view and specific capabilities of self" (Elias 1997 quoted in McKewen 2009). While much of the research into transformative learning in higher education is centred on formal, student-centred learning experiences (Mezirow and associates 2000), in this study the focus is on collective learning at an institutional level. Although an organisation itself cannot 'learn', transformational learning by individuals within the organisation expands the collective consciousness and may transform (change) the world view and collective capabilities of the organisation (Buchan 2010a).

This study forms part of a broader doctoral research project and is part of a series of publications and presentations on this research (Buchan 2008a, 2008b, 2010a, $2010 \mathrm{~b})$. This particular study explores the transformational impact at a variety of levels within Charles Sturt University (CSU) of the introduction of a new online learning environment (OLE) within the institution over the time period 2007-2009. The platform for the OLE is the open source (Sakai) Collaboration and Learning Environment (CLE). CSU is the largest provider of distance education in Australia with some 33,000 students, of whom over two-thirds are enrolled as distance education students.

CSU is a regional, multi-campus, mixed mode (distance/on-campus) university and its campuses are distributed over hundreds of kilometres in New South Wales. The wide range of students and physical locations provide significant challenges for communication and teaching. From the late 1990s onwards, the university had an OLE that consisted primarily of in-house developed systems with an increasing range of tools. The university did not have a learning management systems equivalent and had limited online interactivity or Web 2.0 functionality. The Sakai CLE extends the concepts of similar systems such as learning management systems, content (courseware) management systems and virtual learning environments to use beyond the classroom such as research purposes. Sakai is distributed as free and open source software under an Educational Community Licence (Berg and Korcuska 2009).

The social-ecological systems approach has been used to ground the exploration of the transformational potential of learning technology. Within this approach, the focus remains on maintaining the best possible learning environment for staff and students amidst the constant change within an organisation, and under the influence of external environmental factors.

There has been considerable research into the acceptance, uptake and use of learning technology (Rogers 2003; Hannan 2005; Keller 2005; Benson and Palaskas 2006). There is also a body of research around the change management and implementation of learning technology (Benson and Palaskas 2006; Uys 2009; Conole, White, and Oliver 2007). The social-ecological system model uses two dynamics to describe a changing system: the adaptive cycle and panarchy (Buchan 2008b, 2010b; Walker and Salt 2006). The properties of the social-ecological system 
approach that determine a system's capacity to manage change are its resilience, adaptability and transformability. This research, however, steps outside those areas of knowledge and looks at new ways of understanding changing systems and transformation with a view to improved management practices.

\section{The adaptive cycle}

The adaptive cycle is one of the key dynamics of the social-ecological systems approach. It is grounded in ecological studies and effectively describes the dynamics of an ecosystem and how such a system might respond to changes in the environment. At its simplest, the adaptive cycle has two opposing modes; a development loop, the fore loop; and a release and reorganisation loop, the back loop (Figure 1).

The author has developed the Adaptive Cycle Framework (Figure 2) as a systems analysis tool for understanding and managing the dynamics of a changing environment, in particular the technology-enhanced learning environment, when an educational institution moves through a period of transformation brought about by the introduction of new learning technology (Buchan 2008b; Uys 2009). The Adaptive Cycle Framework will be used here to contextualise the findings of this study and to illustrate the transformation at an institutional level that can be attributed to learning technology. The findings and deep thinking associated with this phase of the research have contributed to the further development of the Adaptive Cycle Framework as it is presented here.

The Adaptive Cycle Framework uses descriptors that are being developed as the notable factors that can be used to build up a picture of the transformation process at the institutional systems level. Because the Framework was adapted from another discipline area, the environmental management field, the original descriptors have been modified for this new applied use (Buchan 2008b). Potential refers to the capital, resources and energy stored in the system and the overall capacity to carry out the core business of teaching and research. For a university, the resources include the physical infrastructure; structural assets such as buildings and equipment, information technology (IT) infrastructure - hardware and software; and the people (i.e. staff and students). Connectedness refers to the relationships, interactions and

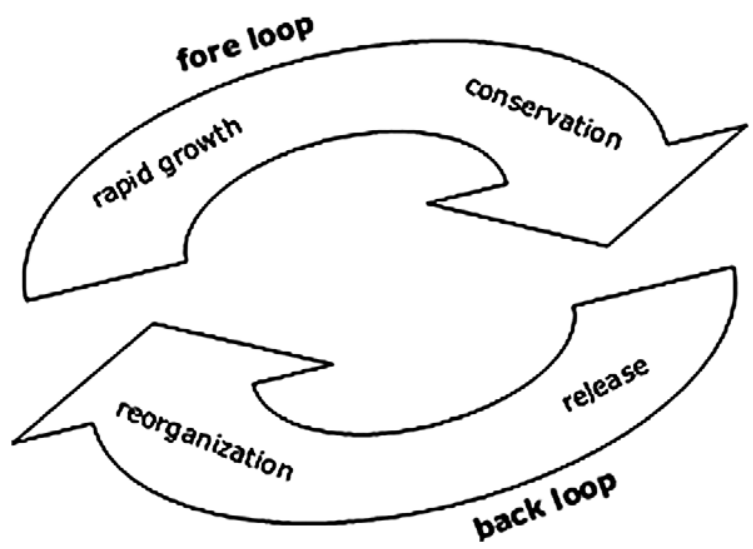

Figure 1. Simple representation of the adaptive cycle (after Walker and Salt 2006). 


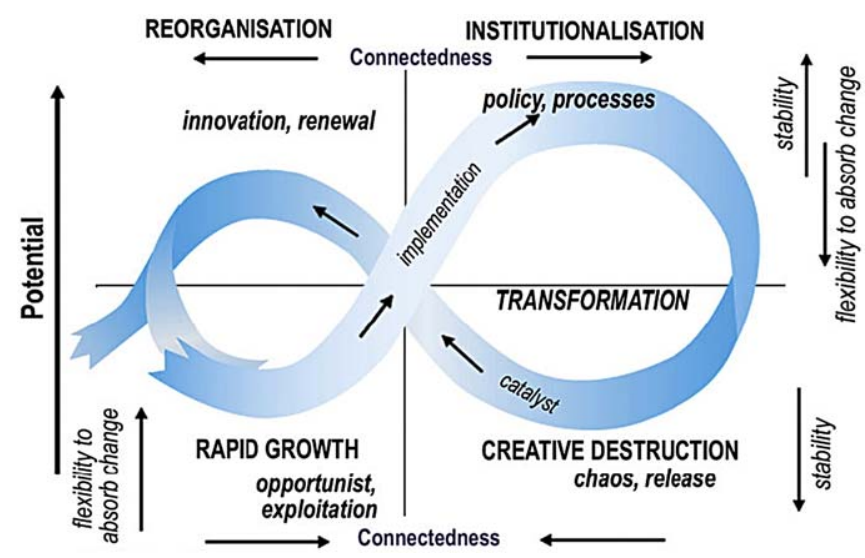

Figure 2. The Adaptive Cycle Framework.

dependencies between the individual components of the system. In technologyenhanced learning environments these connections and interactions include those between the academic staff and learning and teaching support staff, connections between staff and students, the connections between IT support areas and staff and students, amongst others. Stability in this context means staying the same, largely unchanging, balanced, lasting. Policy and processes are the day-to-day formal processes and procedures at micro- and macro-levels that enable an organisation to run efficiently.

Because it is a 'cycle' there is effectively no beginning or end. It is becoming clear through the findings of this research that with respect to the introduction and implementation of learning technology there is also no single ideal place in the adaptive cycle to start transforming and this will vary for each individual situation (Uys 2009). This research investigates how different parts of the institutional system move through transformation since different parts of a system may move at different speeds. The Adaptive Cycle Framework is presented as a metaphor to view and understand a changing system. It provides a way to predict what is likely to happen next and to manage for this in order to provide a smooth transformation. Similarly, although all individuals will need to 'weather' the changes in a system during periods of change, some individuals may be better suited to operating in one phase than another.

There are four phases in the Adaptive Cycle Framework: institutionalisation, creative destruction, reorganisation, and rapid growth. The institutionalisation (conservation) phase is usually the longest phase. The potential of capital, resources and energy stored in the system increases over time as a system moves towards the peak of this phase. Net growth slows and the system becomes increasingly connected, less flexible and thus more vulnerable to internal and external changes.

Disturbances and changes lead to the release phase, referred to as the creative destruction phase. In this brief release phase the dynamics are chaotic, but the destruction that ensues has a creative element (Walker and Salt 2006). Stable relationships, processes and institutional structures will be shaken up. This is a period of release of bound-up resources in which some existing structures fall apart. In nature, the transition from conservation to release phase can happen quickly - for example, when a fire or flood goes through the ecosystem - or more slowly - for 
example, climate change. In higher education the change may be gradual - universities responding to economic trends and competition in the sector. Sudden change can be initiated - for example, changes driven by new government agendas or external environmental factors such as the Global Financial Crisis.

The creative destruction phase is followed by the reorganisation phase in which innovation and renewal can take hold. With learning technology, innovation and experimentation are the order of the day with early adopters likely to play a key role.

In order to harness the power of innovation and experimentation for long-term transformation and renewal of the system, an institution needs to move into the rapid growth phase, which begins the 'mainstreaming' of new processes. In the case of learning technology this might include new ways of teaching and new modes of support for teaching. The rapid growth phase sees an increase in potential and connectedness between the components of the system-associated resources. Rapid growth is characterised by the activity of 'opportunists' who capitalise on the existing conditions and opportunities (e.g. the availability of new learning technology, special project funding, professional development, etc.) to help embed the learning technology as part of the mainstream, institutional system.

Because it is a 'cycle' there is effectively no beginning or end. It is becoming clear through the findings of this research that with respect to the introduction and implementation of learning technology there is also no single ideal place in the adaptive cycle to start transforming and this will vary for each individual situation. This research investigates how different parts of the institutional systems move through transformation since different parts of a system may move at different speeds. The Adaptive Cycle Framework is presented as a metaphor to view and understand a changing system. It provides a way to predict what is likely to happen next and to manage for this in order to provide a smooth transformation (Uys and Buchan 2009). Similarly, although all individuals will need to 'weather' the changes in a system during periods of change, some individuals may be better suited to operating in one phase than another.

\section{Methodology}

The period covered in this study was 2007-2009. Data collection extended prior to and beyond this period to provide an important historical background to the changing technology-enhanced learning environment at the university. A case-study approach has been used with a regional, multi-campus Australian university as the single case study. This qualitative research study primarily uses an ethnographic approach with the researcher as participant (Wiersma 2000; Walter 2006).

A variety of data collection methods were used to address the many-faceted research study. In order to address the aims of this particular paper, a selection of data was made from the extensive data collection. In 2008, during the first full year of the implementation of the new OLE, targeted in-depth structured interviews were done with 16 staff who had been involved in the implementation, support and/or use of learning technology across the university. Those interviewed were representative of a cross-section of the university staff involved with learning technology: academics, faculty members in leadership positions, and staff supporting learning and teaching such as learning and teaching services staff, IT management staff and student support staff. These interviews raised wide-ranging questions with the primary 
focus being on gathering information to understand attitude to change and transformation at an individual and at an institutional level. Late in 2009, six further interviews were conducted to explore aspects of transformation at the institutional level in more depth. The focus of the interviews relevant to this paper is the two-level focus on the transformational impact of change associated with learning technology at both individual and institutional levels. The interviews also explored aspects of educational management in order to identify issues which staff and students face in the current learning environment and to determine effective strategies that can be used in the successful implementation and support of learning technology.

In keeping with the ethnographic approach a journal was kept of personal notes and reflections during and after regular divisional/unit meetings, professional development workshops, during local, national and international conferences and through formal and informal discussions in a variety of groups. These personal notes have been used to develop an understanding of the overall 'system' that is involved with the introduction and support of learning technology at the university. Aspects of this system include timelines, roles of individuals and groups and inter-personal relationships. These notes and reflections identify the potential impact factors at organisational level and from the broader higher education environment.

Secondary sources of data included historical documents, memos, university records and a variety of personal communications that were used to build up a picture of how the technology-enhanced learning environment is changing. These records included committee and working group agendas and minutes; working party reports; strategic plans; official memos; policy and regulatory statements; newsletters and media releases; informal personal communications and user surveys around the use of learning technology. Over 300 documents, covering 1998-2010, were collected. The documents were a source of data that contributed towards identifying some of the potential impact factors that are important in institutional transformation associated with learning technology. The records were collated in Excel and coded according to type of record, date of publication/writing, author, audience and key words.

\section{Findings}

The findings are grouped into two main areas in keeping with the research aims. Firstly, evidence is presented that contributes towards identifying the transformational impacts of learning technology (Table 1 and Table 2). Secondly, evidence is presented that contributes to demonstrating the efficacy of the Adaptive Cycle Framework as a metaphor for framing transformation at an institutional systems level (Table 3).

The responses of participants in the interviews, researcher observation and reflection, and documentary evidence have been used to compile the data below. The primary data sources (interviews and observation) have been combined with the secondary data sources (institutional surveys, reports, memos, conference proceedings, etc.). There is no difference in weighting and overall importance given to the primary versus secondary data sources. Each serves its own purpose in contributing to the overall picture of the transformational impact of learning technology. As transformation is essentially 'a change', both positive and negative impacts have been noted. 
Table 1. Summary of transformational impacts of learning technology at individual level.

Academic staff (some of these attributes also Learning and teaching services support staff ${ }^{\mathrm{a}}$ apply to other staff ${ }^{\mathrm{a}}$ )

+ more adaptable to new technology, prepared to try new things ${ }^{\mathrm{a}}$

\# new skills in a range of learning

management systems and Web 2.0 tools, and

digital media tools (e.g. Captivate)

+ more (constructively) critical of new

\# new skills in designing learning

technology

+ awareness that learning needs should drive the technology, Interact is only a set of tools experiences for online medium, designing digital media - heading towards a base-level technology expertise

+ stepping up in providing professional development around use of technology and embedding subjects in the e-learning environment

\# reflecting on learning design in new + increased workloads media $^{\mathrm{a}}$

\# new skills in designing blended learning experiences $^{\mathrm{a}}$

+ new skills, learning management systems and wide range of Web 2.0 tools, Captivate, Dreamweaver, designing learning experiences for online ${ }^{a}$

\# enabling the use of new pedagogies and learning approaches with students

+ higher expectations of the standard of technology ${ }^{\mathrm{a}}$

+ lack of trust in university IT systems (where some new tools have not worked well)

+ increased workloads $^{\mathrm{a}}$

\begin{tabular}{ll}
\hline Student services support staff $^{\text {a }}$ & Students \\
\hline $\begin{array}{l}\text { Internet access and communication } \\
\text { systems have transformed work practices } \\
\text { and lives }\end{array}$ & $\begin{array}{l}\text { + immersion in technology creates digital } \\
\text { natives who adapt quickly to using different } \\
\text { learning technologies } \\
\text { value the facility to have a social presence } \\
\end{array}$ \\
$\begin{array}{l}\text { + at micro level, technology has solved } \\
\text { specific communication issues for distance } \\
\text { education students }\end{array}$ \\
$\begin{array}{l}\text { at micro level, technology has solved } \\
\text { specific communication issues for distance } \\
\text { education students }\end{array}$ & \\
\hline
\end{tabular}

Note: +, data from interviews; \#, data from researcher observation and document analysis.

A summary of some of the observed transformational impacts of learning technology at an individual level is given in Table 1 .

A variety of data have been collected and synthesised to determine key areas of the contribution of learning technology to the transformation of learning and teaching. From the data, six key areas emerged in the contributions of learning technology to transforming learning and teaching in the university. Table 2 summarises the selection of evidence that illustrates some of these key areas.

Table 3 illustrates transformation at an institutional level. The phases of the Adaptive Cycle Framework have been used to contextualise some of the evidence to demonstrate the events and features related to the introduction of the new online 


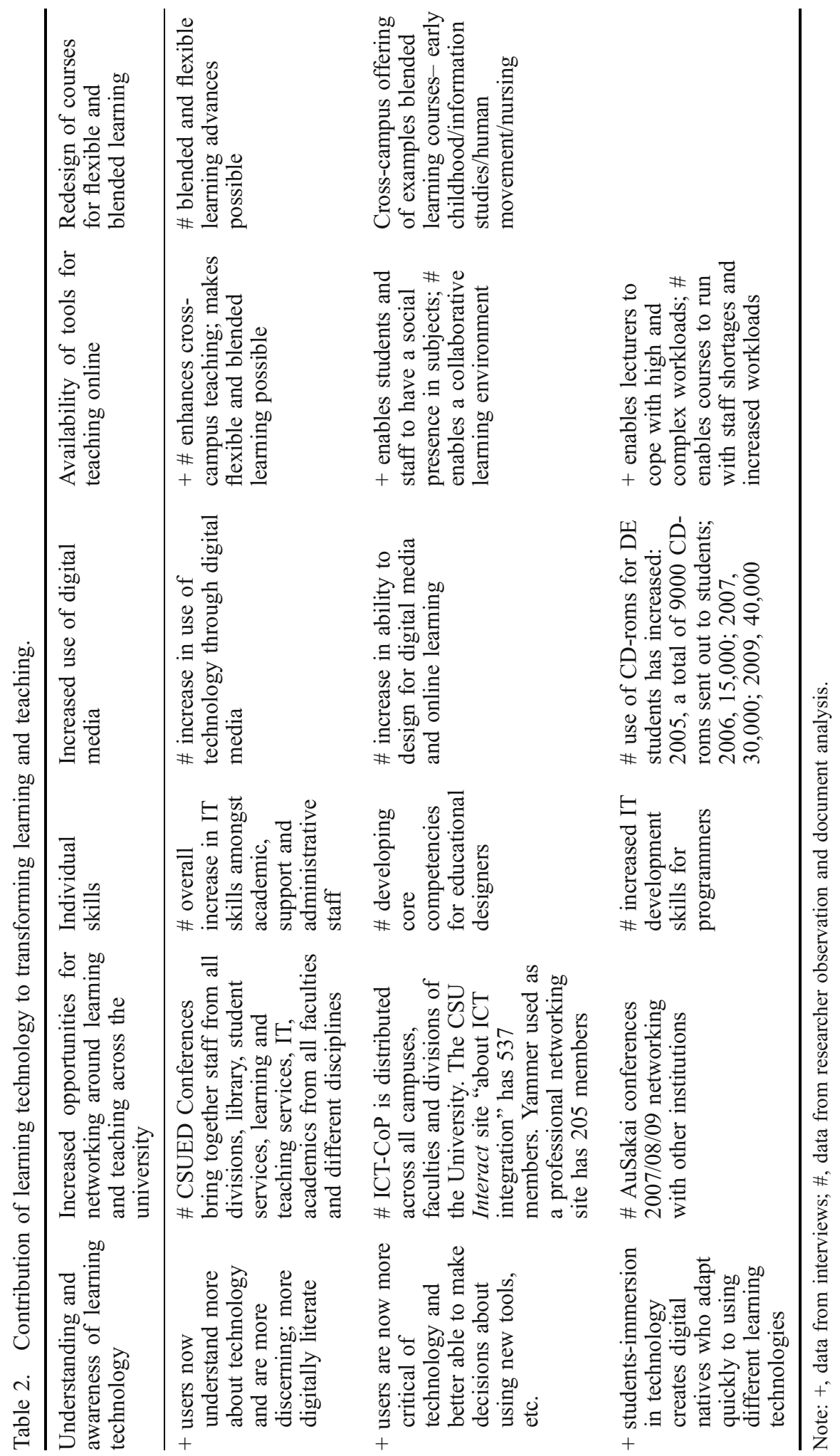




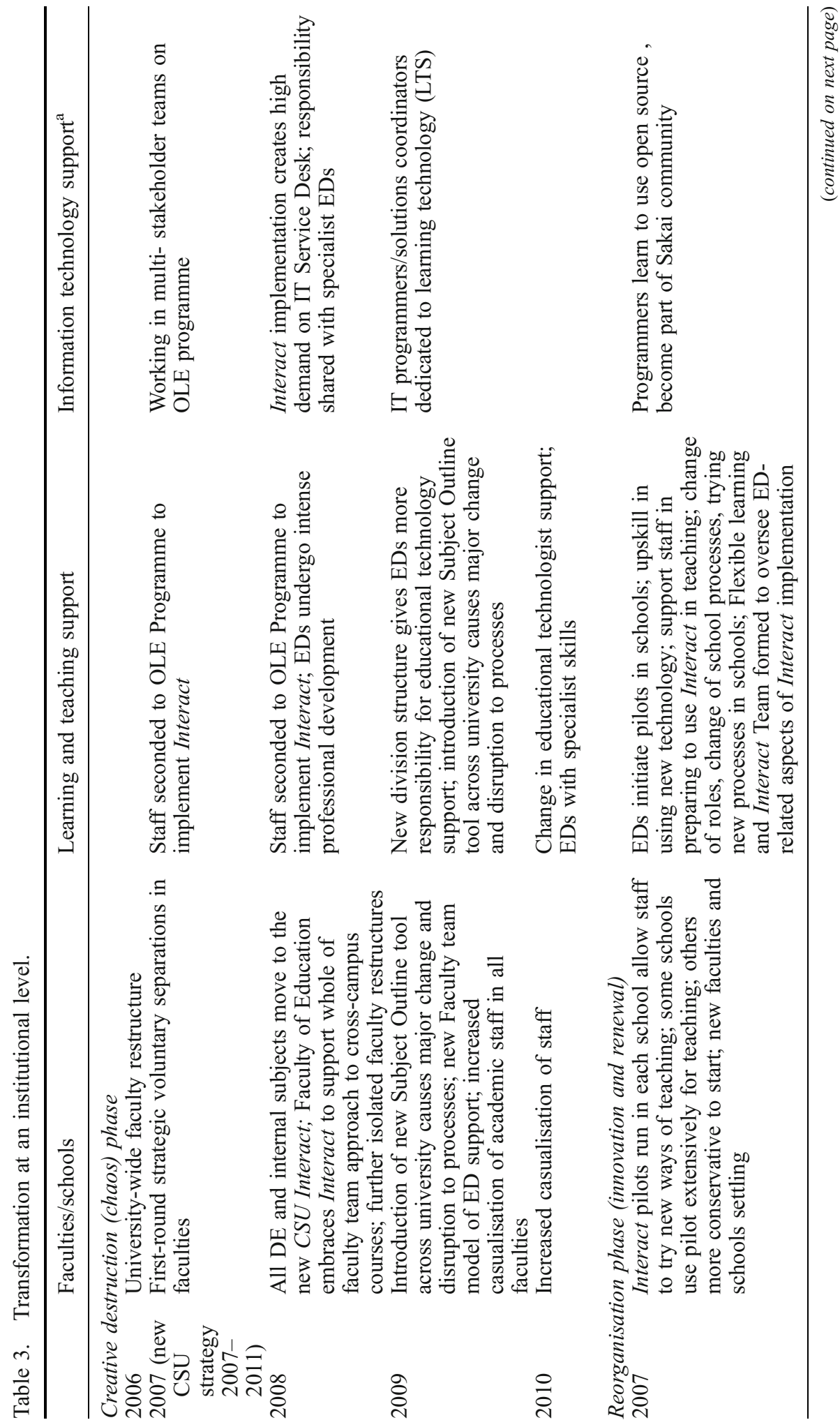




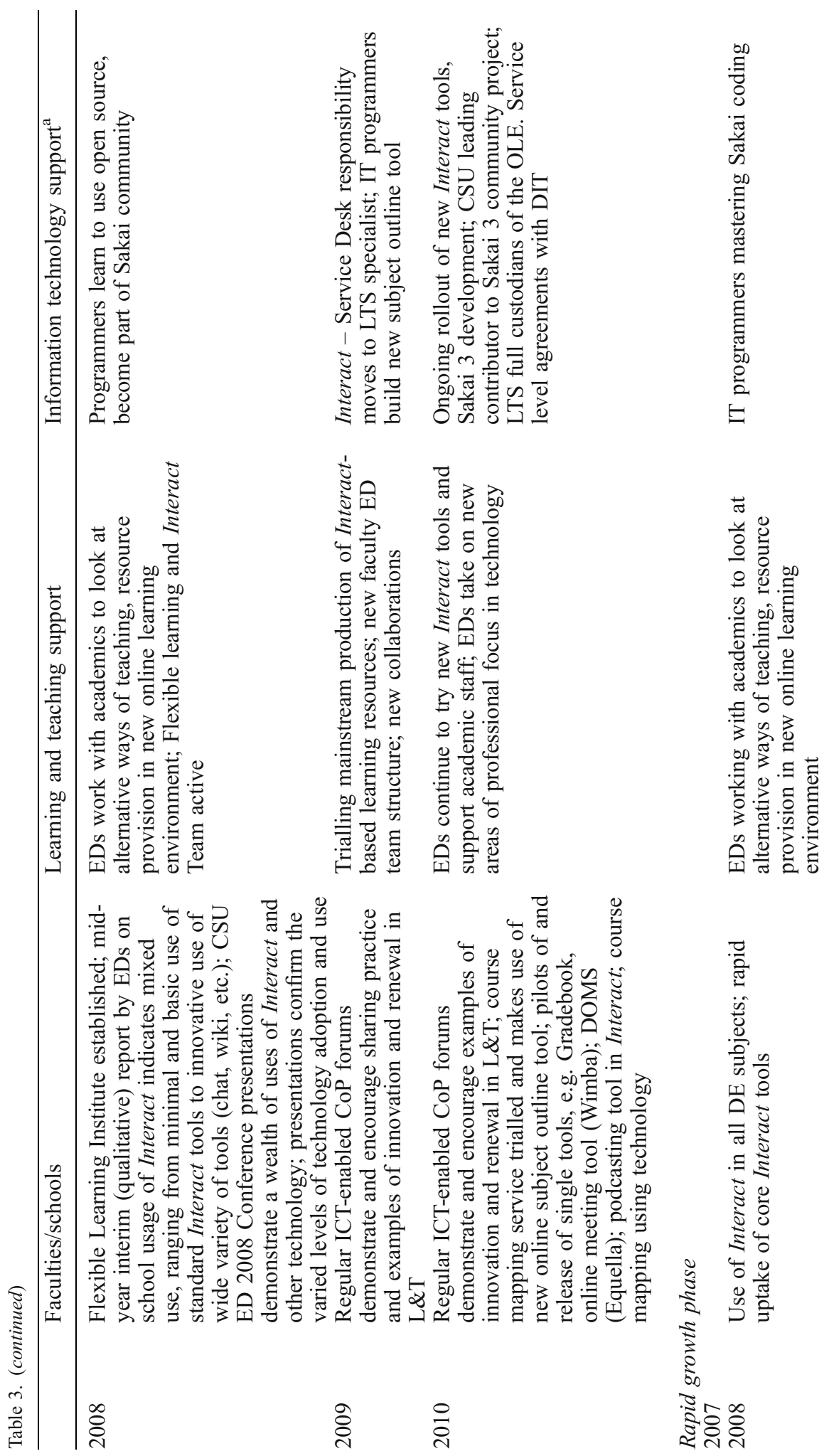



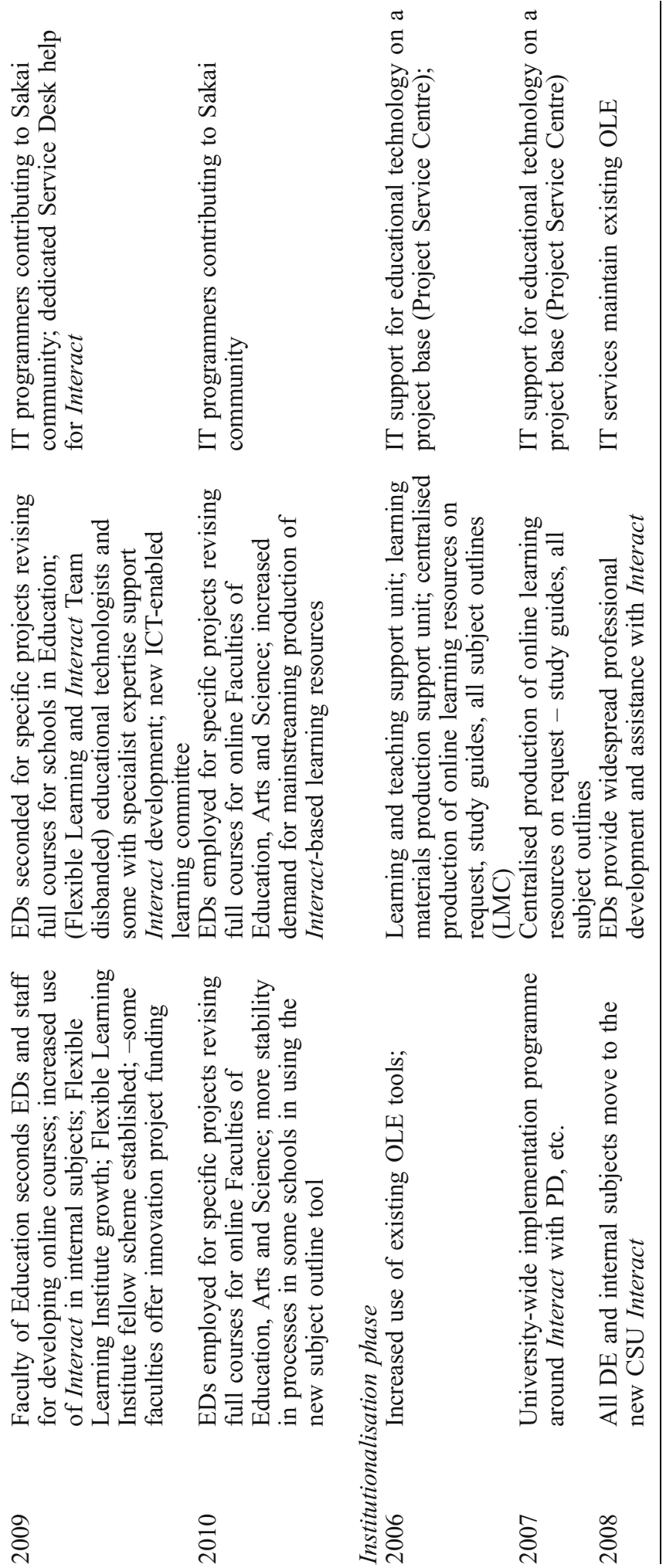


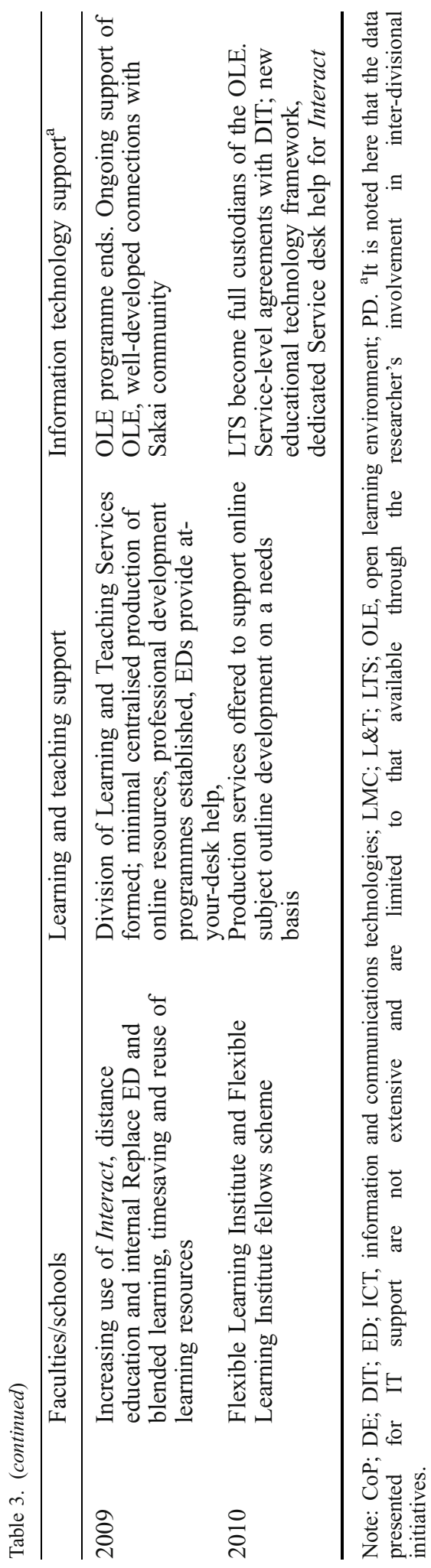


learning environment that characterise each of the phases of the Framework. For reasons of space, only a snapshot of the evidence is provided.

The events and observations that have been identified in each phase of the transformation process have been used to extract and generalise some features that appear to characterise each phase. These features can be used to identify what phase a part of an institution might be in with respect to an institutional transformation process. It is acknowledged that these features are not yet comprehensive and are only a starting point for discussion and ongoing research. There may also be some limitations in their generalisability to other organisations since this research is based on a single case study. These features are as follows:

- Creative destruction. Loss of normal connections, changes in interactions amongst stakeholders, inefficiencies in operations, loss of dependencies, changes in roles, freeing up of resources/people from old ways of doing things.

- Reorganisation. Innovation, trying new ways of doing things, trial and experimentation in day-to-day operations, sharing of ideas, questioning of status $q u o$, pilots and trials of new technology, teams/communities of practice set up, inefficiencies, leadership emerges.

- Rapid growth. New processes and procedures developed, sharing of practice, acceptance of technology, improved efficiency, leadership cemented, creating and taking opportunities to make the most use of new technology and available support opportunities, new connections, interactions and dependencies forming, collaboration.

- Institutionalisation. Improved efficiencies in operations, long-lasting relationships develop, ongoing development of processes, ongoing small-scale renewal and review and improvement of processes, building up of resources, centralised services have well-developed processes and procedures.

\section{Discussion}

It should be noted that prior to the introduction of the new OLE there has always been an extremely active learning and teaching focus at the university with school and faculty-based opportunities for people to share practice, along with regular learning and teaching conferences. Since the 1990s, the introduction of new learning technology tools has been accompanied by sound research and a striving for continuous improvement (Chan, Lee, and Mcloughlin 2006; Dalgarno 1998; Burr and Morton-Allen 2001). This study was limited to looking at the transformational impact of learning technology over a particular time frame that coincides with the introduction of a new OLE and the move to Web 2.0 capacity within the university to support university strategic directions.

When investing in new technology, institutions often look to a demonstration of the 'value for money' and want measureable, tangible benefits. This research suggests that the benefits go beyond new ways of teaching and improved student learning.

At the individual level there is evidence of transformation in a number of areas (Table 1 and Table 2). There has been a transformation in the skills of academic and support staff in using technology and Web 2.0 tools specifically and an increased capability in designing a variety of learning experiences to make use of 
the new tools. For educational designers the core role has changed and has necessitated a significant increase in skills and knowledge. Student support services staff noted that the access to technology has transformed the way they can teach and support students. There have been changes in individuals' attitudes to technology. A pertinent transformation that has been noted is that some academic and support staff are now more discerning and aware of technology, have higher expectations and report less tolerance of systems that do not match up to expectations. For IT programmers and developers there has been a major increase in individual skills consistent with the development of new collaborative processes in the Sakai community for the open source software development.

At the institutional level, the implementation of the new OLE, CSU Interact, across the whole of the institution during 2007/08 affected the entire university in some way, from faculties to student support services and staff administration. This study has focused on a number of key areas and stakeholders directly involved with support of the academic staff and the technology itself.

If one was to position the case study university in the Adaptive Cycle Framework with respect to learning technology - more specifically Web 2.0 technology the status quo in 2006, prior to the beginning of the implementation of CSU Interact, would have been in the late institutionalisation phase. At this time, because of its lack of Web 2.0 capacity, the university was extremely vulnerable to changes in the external environment (Buchan 2008a). The beginnings of the implementation of CSU Interact in 2007 can be said to mark the start of the creative destruction phase associated with the move to the new OLE and Web 2.0 technology. At that time this was not the only phenomenon to cause 'creative destruction' for faculty restructures and university-wide staffing rationalisations targeting academic staff made an impact in 2006/07 and for some faculties this continued in 2008/09. Each year following the initial implementation of CSU Interact, new university initiatives have been identified as having caused some degree of disruption (Buchan 2010b). Some stakeholders such as the academic staff appeared to be affected by more changes to systems, processes and technology than others.

There has been constant innovation and renewal in all key areas. For those responsible for implementation of the new OLE, IT services and learning and teaching services, the innovation and renewal has taken place earlier than the 'receivers' of the new technology (i.e. the faculties). There were ongoing new initiatives associated with learning technology and an associated need for constant innovation and renewal in a variety of areas including institutional structures and operations. Evidence from the CSU Education 2005, 2008 and 2009 internal conferences demonstrate that innovation and renewal in learning and teaching with technology are strong in most faculties. Information and communications technology-enabled Community of Practice Forums initiated in 2009 have provided the opportunity for staff to share their innovation and use of learning technology. Some faculties and schools demonstrated a tendency towards a constant, self-generated state of innovation and renewal, while for others innovation and renewal in learning technology has been the consequence of a more 'involuntary' move into the creative destruction phase and the ensuing innovation and renewal as a result of the introduction of the new OLE.

There is less evidence to illustrate widespread progress through the rapid growth phase. The evidence illustrating rapid growth tends to be made up of the many small initiatives that began 'mainstreaming' the use of the new technology and 


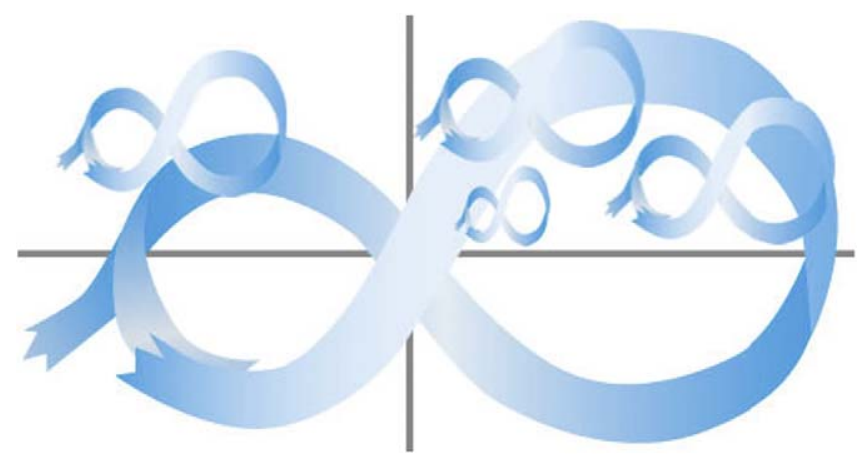

Figure 3. Representation of a dynamic and stable institutional phase.

associated support processes. At less than two years after the introduction of CSU Interact this may be expected, especially considering the other external factors and technologies that have impacted. The introduction of a new, university-wide, online subject outline system (MSI) in 2009 has been a significant impact factor that has caused a major disruption for faculties and learning and teaching support staff, and appears to have affected the ongoing consolidation of the use of the new OLE and other technologies. It has also been difficult to clearly distinguish between innovation and renewal, the rapid growth phase and the move towards the early institutionalisation phase. This is an area that requires more exploration in order to refine the model.

There is evidence to confirm that parts of the system have moved into a new institutionalisation phase with respect to learning technology. There is the beginning of building-up of resources such as learning and teaching support services and professional development programmes. There are IT staff dedicated to learning technology development, Flexible Learning Institute programmes and fellows to promote the scholarly use of learning technology. There has been major structural change at institutional level (learning and teaching services and IT services) to support ongoing strategic directions in learning technology (Buchan 2010b). The system has, however, not yet reached a stability phase with respect to learning technology. This is to be expected since the institution is still in a rapid growth phase with respect to new learning technology.

\section{Conclusions and future directions}

Transformation is not always smooth and predictable. When analysed using the Adaptive Cycle Framework, different parts of an institutional system appear to move through the phases of transformation at different speeds. For maximum transformational benefit of major technological change, the change agents responsible for implementing new learning technology and associated support processes (IT support staff, learning and teaching services, faculty leaders, etc.) need to be prepared for regular periods of creative destruction; to spend time in the innovation and renewal phase; and to develop the necessary skills and processes to assist their own areas to move quickly through the rapid growth phase in order to reach the relative stability of the institutionalisation phase for those whom they support. In reality, in this study there were many different initiatives and changes taking place 
at any one time in the university, the combined impact of which appeared to affect the realisation of the transformational potential of new learning technology. The message for management then, is to take a holistic and long-term approach to identifying the many different impact factors that need to be taken into consideration when managing for an effective implementation of new learning technology initiatives.

On the evidence presented, the earlier assumption that all parts of an institutional system will move/need to move through all the phases of the Adaptive Cycle Framework during the introduction of a major new learning technology is now questioned. With the need to constantly upgrade systems and to keep pace with emerging learning technologies, institutional systems need to be responsive and to have sufficient support structures in place at the institutional level to be able to quickly and effectively implement new learning technology. An assumption was made earlier that for institutional transformation to take place the starting point for the institution would be in the institutionalisation phase. It is suggested here that transformation can begin at any phase in the adaptive cycle. The initiation of transformation can come effectively from areas strong in innovation and with a need for constant renewal. However, the effectiveness of that transformation will depend on how well the process is managed and supported in the institution.

A time frame of less than three years appears to be too short for a complete transformation to take place in the case-study institution and for the institution to return to something resembling the institutionalisation phase; that is, stability, building up resources and connections, developing policies and new processes following the introduction of the new online learning environment and Web 2.0 technology. The original characteristics/properties by which the stable, institutionalisation phase was defined have also been questioned. What has emerged from this study is that the institutionalisation phase can perhaps be better described as 'a period when normal business operations, i.e. effective teaching and student learning, can efficiently take place while withstanding minor internal and external changes'. Innovation and change is a good thing, but can be costly in time and resources. This does not necessarily mean that there should be no change in the institutional processes, but that the processes and the people are adaptable and resilient (i.e. able to absorb change). In terms of the Adaptive Cycle Framework, a possible 'stable' but dynamic institutionalisation phase situation could be illustrated by rapid cycling (adapting) within the institutionalisation phase (Figure 3) and occasional generation of transformation from within the reorganisation (innovation and renewal) phase. This would facilitate innovation and renewal while retaining productivity and stability. Learning technology should never be stable and unchanging. A stable state is perhaps more effectively described as one of dynamic stability. This is an area for further study through the exploration of two more properties of the social-ecological systems approach - resilience and adaptability.

This study has unearthed a 'chicken or the egg' conundrum. Although learning technology is an important part of the future of educational institutions, the adaptability of the organisation and capacity to predict, plan for and support ongoing changes in learning technology is an important part of realising the transformational potential and effectiveness of learning technology. The impact of technology spreads beyond the user level; that is, simply having access to appropriate technology for particular learning and teaching purposes. If an educational organisation truly embraces learning technology as strategically important to its future, then it 
will need to do more than choose and implement new systems and applications. It will need to prepare to undergo significant transformation in a variety of areas to support the vision for learning and teaching and the institution's technology needs of the future.

\section{Note}

1. See Sakai website: http://sakaiproject.org.

\section{References}

Benson, R., and T. Palaskas. 2006. Introducing a new learning management system: An institutional case study. Australasian Journal of Educational Technology 22, no. 4: 54867.

Berg, A.,and M. Korcuska. 2009. Sakai courseware management. The official guide. Ed. J. Lumsden, S. Mangarole and A. Shanker. Birmingham: Packt Publishing.

Buchan, J. 2008a. Rethinking management strategies for the online learning environment. Paper presented at ALT-C Rethinking the digital divide, 9-11 September 2008, in Leeds, UK.

Buchan, J. 2008b. Tools for survival in a changing educational technology environment. Paper presented at the Where are you now in the landscape of educational technology? Ascilite conference, December, in Melbourne.

Buchan, J. 2010a. Developing a dynamic and responsive online learning environment: A case study of a large Australian university. International Journal of Open Source Software and Processes 2, no. 1: 32-48.

Buchan, J.F. 2010b. Putting ourselves in the big picture: A sustainable approach to project management for e-learning. The Journal of Distance Education 24, no. 1: 55-76.

Burr, L., and M. Morton-Allen, 2001. Inventing a better mouth trap: The development and implementation of forum software at Charles Sturt University. Paper presented at the AusWeb01 Seventh Australian World Wide Web Conference, in Coffs Harbour, Southern Cross University.

Chan, A., M. Lee, and C. Mcloughlin. 2006. Everyone's learning with podcasting: A Charles Sturt University experience. Paper presented at the Ascilite conference, December, in Sydney.

Conole, G., S. White, and M. Oliver. 2007. The impact of e-learning on organisational roles and structures. In Contemporary perspectives in e-learning research: Themes methods and impact on practice, eds. G. Conole and M. Oliver, 69-81. Abingdon: Routledge.

Cumming, G., D.H. Cumming, M. Cumming, and C.L. Redman. 2006. Scale mismatches in social-ecological systems: Causes, consequences, and solutions. In Exploring resilience in social-ecological systems. Comparative studies and theory development, ed. B. Walker, A. Anderies, A. Kinzig, and P. Ryan, 23-40. Melbourne: CSIRO.

Dalgarno, B. 1998. Tools for authoring constructivist computer assisted learning resources: A review. Paper presented at the FlexibillTy: The new wave Ascilite conference, December, in Wollongong.

Hannan, A. 2005. Innovating in higher education: Contexts for change in learning technology. British Journal of Educational Technology 36, no. 6: 975-85.

Keller, C. 2005. Virtual learning environments: Three implementation perspectives. Learning, Media and Technology 30, no. 3: 299-311.

Kezar, A. 2003. Synthesis of scholarship on change in higher education. Higher Education Policy 16, no. 1: 39-53.

McKewen, L. 2009. Transformational learning. Research Briefing, University of Gloucestershire, Pedagogic Research and Scholarship Institute, Gloucester.

Mezirow, J., and Associates. 2000. Learning as transformation: Critical perspectives on a theory in progress. Jossey Bass Higher and Adult Education Series. San Francisco: Jossey Bass.

Rogers, E.M. 2003. Diffusion of innovation. 5th ed. New York: Free Press. 
Uys, P. 2009. Change and innovation strategies during the implementation of an open source LMS: An Australian case study. Research, Reflections and Innovations in Integrating ICT in Education. Paper presented at the V International Conference on Multimedia and ICT in Education (m-ICTE2009), in Lisbon, Portugal.

Walker, B., and D. Salt. 2006. Resilience thinking. Washington, DC: Island Press.

Walker, B., J. Anderies, A.P. Kinzig, and P. Ryan, eds. 2006. Exploring resilience in socialecological systems. Comparative studies and theory development. Melbourne: CSIRO Publishing.

Walter, M. 2006. Social research methods: An Australian perspective: Oxford University Press.

Wiersma, M. 2000. Research methods in education: An introduction. MA: Allyn and Bacon. 